In the former, even people classed as 'unemployables' have been made self-supporting. In India he suggests a start could most easily be made with an educational co-operative colony in which young persons could work and receive their education. Elderly persons might also be included to act as leaders, or to work in departments of their own. In order to start a fund for experiment on the lines advocated by Capt. Petavel, the Mayor of Karachi has announced that he will give Rs. 5,000 and 50 acres of good land near Karachi.

\section{Re-equipment of Collieries and Steelworks}

IN the supplement to the Daily Telegraph of March 19, Dr. A. H. Railing says that the need for the reorganisation of certain of the basic industries of Great Britain is urgent. As a result of recent applications of scientific knowledge, great advances have been made in developing new plant for the economic mining of coal and the manufacture of iron and steel products. In recent years the grouping of collieries makes it possible to use large turbo-machines and thus considerably lowers the cost of generating electric power. This solution of the problem of the handling and transport of coal will contribute greatly to the economic success of the undertaking. A colliery equipped with a modern coal-cleaning installation can command higher prices for its output. Loss and waste due to the breakage of coal can now be reduced to a minimum by using anti-breakage devices. By grouping together iron and steel works it would be possible to utilise the by-product gases of the iron and steel industry. An installation of large turbo-generator units in such a station would enable it to have a thermal efficiency as high as that obtained in the largest modern power station. The by-product gases from the industry would in this way acquire the same heat value as the coal used in coal-fired power stations. Many of the rolling mills in Great Britain have been installed for very long periods and their retention in service militates against securing the high quality of product demanded to-day. An electrically driven rolling mill of modern design can be regarded in the light of a precision tool, capable of an output of material possessing the highest degree of accuracy obtainable in rolling practice. The electric furnace also opens out great possibilities. One of the valuable properties of the high-frequency electric furnace is that, when operating, it gives rise to an automatic stirring action which secures a uniform product.

\section{Street Traffic Signals, 1868-1934}

IN 1868 the City of Westminster introduced a method of mechanical signalling to help the police to control the traffic. A semaphore, having a red and green gas lamp for night use, was employed, but unfortunately an explosion put an abrupt end to this experiment. Early in this century, road signals similar to railway signals were used for controlling a few tramways and also the traffic on Tower Bridge. So far back as 1918, colour light signals were used to control street traffic in New York. The Siemens and
General Electric Railway Signal Co. (S.G.E.) installed the first modern British traffic signal at a busy road junction in Wolverhampton in 1926. The most recent development of the vehicle-actuated signals is the 'Autoflex' system of the S.G.E., a full description of which is given in the Engineering Supplement of the Siemens Magazine for April. It was first brought into use in November 1933 and there are now several installations giving very satisfactory service. In this system vehicles approaching a road junction pass over pneumatic detector mats, installed in the paths of the various traffic streams, and so notify their movements to an electrically operated controller. The mats are equivalent to the eyes and ears of a traffic policeman. If vehicles leave the intersection on the wrong side of the road the mats are insensitive. The top of the mat is rounded and projects slightly above the road level presenting a good striking face, so that it is not possible for high-speed vehicles or caterpillar tractors to ride over it without registering. If no suitable gap occurs within a predetermined time, the continuous stream is arbitrarily interrupted and the right of way transferred. There is no necessity for long 'amber' periods since signal changes take place only when the intersection is clear; two or three seconds are generally sufficient. The power required for a controller is only about 30 watts, which is less than that required by an ordinary lamp.

\section{Crystalline Structure and Failure of Metals}

THE eighth Edgar Marburg lecture of the American Society for Testing Materials was delivered by Dr. H. J. Gough, his subject being "Crystalline Structure in Relation to Failure of Metals - especially by Fatigue". Dr. Gough dealt almost exclusively with the results of X-ray examination of metals, and the paper contains what is probably the fullest résumé yet given of the subject. Some indication of the ground traversed will be obtained from the fact that the bibliography contains no less than 175 separate references. Starting off with a general discussion of the nature of the atomic bond and of the structure of solids in connexion with the basic problem of failure under stress, the methods of preparation of single crystals of metals, and crystal structure as revealed by X-ray investigation, Dr. Gough then proceeded to consider more specifically the distortion of single metallic crystals under simple static stresses, the influence of the crystal boundary upon strength and distortion and the effects of coldworking upon single crystals and multicrystalline aggregates. Coming to the subject of failure under 'fatigue' conditions, Dr. Gough dealt with metals crystallising in the face-centred cubic, in the closepacked hexagonal (discussing incidentally the twinning of zinc), in the body-centred cubic, and in the face-centred rhombohedral lattices. Finally, he considered the behaviour of single crystals as com. pared with that of multicrystalline metals. Dr. Gough's conclusions are not yet everywhere accepted, but whatever the individual opinions of readers of the lecture may be, it will be universally welcomed as providing, in a readily accessible form, an almost 